\title{
O LABORATÓRIO DE CIÊNCIAS E A PRÁTICA DOCENTE DE UM GRUPO DE PROFESSORAS DE BIOLOGIA: RELATO DE UM PROCESSO DE REFLEXÃO COLETIVA
}

Fernando Cesar FERREIRA ${ }^{1}$

Lenice Heloísa de Arruda SILVA ${ }^{2}$

RESUMO: A estreita vinculação entre a visão de ciência do professor e a sua materialização na forma de atividades experimentais revela alguns dos caminhos construídos na prática docente. Considerando isso e tendo como foco o $9^{\circ}$ Ano do Ensino Fundamental, este trabalho relata e discute o processo de intervenção e reflexão coletiva sobre mudanças nas relações entre o uso de experimentos e demonstrações em ciências, em particular a Física, e a prática docente de um grupo de professoras de Biologia da rede pública de ensino de Dourados-MS.

PALAVRAS-CHAVE: Formação de professores. Laboratório de ciências. Ensino de ciências.

\section{INTRODUÇÃO}

Este trabalho relatar a experiência vivida pelos autores da dinâmica de processos de reflexão de um grupo de professoras de ciências que atuam no $9^{\circ}$ ano do ensino fundamental sobre o papel de práticas de experimentação e demonstração de conceitos físicos. Em um processo de reflexão compartilhada com pesquisadores de ensino de ciências de uma universidade federal, são colocadas para debate as questões: para que serve o laboratório de ciências? Qual o papel do professor durante elou nas atividades experimentais?

Pesquisas em ensino têm demonstrado a eficácia de atividades envolvendo demonstrações e experimentos na percepção e estruturação de conceitos físicos em aulas de ciências (CARVALHO; PEREZ, 2006; ARRUDA; LABURU, 1998). Porém, dois fatores importantes influenciam a realização de atividades experimentais no ensino de ciências: a formação em Física do professor que conduzirá as demonstrações e

\footnotetext{
${ }^{1}$ Doutor em Educação. USP - Universidade de São Paulo. Professor. UFGD - Universidade Federal da Grande Dourados. Dourados - MS - Brasil. 79825-070 - fernandoferreira@ufgd.edu.br.

${ }^{2}$ Doutora em Educação. UNIMEP - Universidade Metodista de Piracicaba. Professora Associada. UFGD - Universidade Federal da Grande Dourados. Dourados - MS - Brasil. 79825-070 lenicesilva@ufgd.edu.br.
} 
experimentos e a percepção desse professor do papel do laboratório no ensino de ciências nas escolas.

Comecemos com o primeiro. Em grande parte das escolas o responsável por discutir Física no $9^{\circ}$ ano do ensino fundamental é o licenciado em Biologia. No entanto, a matriz curricular das licenciaturas em Ciências Biológicas costuma costuma reservar apenas um semestre para Física, compactando discussões sobre mecânica, termodinâmica e eletricidade ${ }^{3}$. Em cada uma dessas áreas existe pelo menos um conceito estruturante de grande magnitude: força em mecânica, transformação de energia em termodinâmica e campo em eletricidade. Não se pode esperar que o licenciando adquira a mestria necessária para poder relacionar os conhecimentos científicos com a ciência escolar e ainda com aqueles que os alunos já trazem para as aulas em tão pouco tempo. Esse modelo de formação de professores pauta-se em um paradigma tecnicista que desconsidera, entre outros fatores, a necessidade do professor refletir constantemente sobre a sua prática (LIBÂNEO, 2006). Ou seja, de acordo com a maioria dos programas das licenciaturas em ciências biológicas do país, em algum momento de sua graduação o futuro professor de ciências terá que cursar uma disciplina ligada a Física e que, em geral, surge desconectada das necessidades do futuro professor. Forma-se assim um quadro que se contrapõe a um elemento importante para o desempenho adequado do professor: o domínio do conteúdo a ser ensinado.

O professor tem de dominar os conteúdos a ensinar. Esta evidência deveria ser acompanhada não apenas de um conhecimento dos elementos de programas, mas também de uma visão mais geral da disciplina a ensinar, em termos de princípios organizadores, de campos nocionais, de tramas conceituais. Trata-se de entrever a disciplina não como um patchwork sem unidade correspondendo cada elemento a um conceito, mas como mosaico expressivo constituído por conceitos ligados uns aos outros. (ASTOLFI; DEVELAY, 2006, p.123).

\footnotetext{
${ }^{3}$ Os nomes dados à disciplina podem ser os mais variados: Fenômenos Físicos, Física e Biofísica, Física para Ciências Biológicas, Introdução à Física etc. Em comum está o programa que basicamente é dividido em três partes: sistemas dinâmicos, termodinâmica e eletrodinâmica. Ótica (formação de imagens, lentes etc.), em geral, não faz parte da ementa. Em alguns cursos são contemplados conceitos básicos sobre radiação, aplicações das radiações, proteção e efeitos radiológicos. Casos interessantes são os da Licenciatura em Ciências Biológicas da UFSC que oferece a disciplina "Física para o Ensino de Ciências" e o da UFRGS que na Licenciatura em Ciências Biológicas para Professores Leigos oferece a disciplina "Fenômenos Físicos" em três semestres. No primeiro ano da Licenciatura em Ciências Biológicas da UFGD é oferecida a disciplina "Física" com duração de um semestre. Na quase totalidade das disciplinas de Física oferecidas para as Licenciaturas em Ciências Biológicas não é reservado tempo para atividades de laboratório.
} 
Trata-se, portanto, de questionar se os programas dos cursos de licenciatura em Ciências Biológicas dispõem de tempo suficiente para que o acadêmico se aproprie minimamente de saberes necessários para planejar, desenvolver e aplicar atividades envolvendo o Ensino de Física.

O segundo fator trata da imagem de ciência que o futuro professor desenvolve ao longo de sua formação e como essa se relaciona com atividades práticas que podem ser desenvolvidas em sala de aula.

Em geral, a imagem que se cria do conhecimento científico é que este é confiável e capaz de explicar, prever e justificar fenômenos da natureza, pois ele é firmemente fundamentado e comprovado objetivamente pelo "método científico", considerado como único que consiste na coleta de dados por meio de rigorosa observação e experimentação. É dos dados coletados que, depois de analisados, derivam as leis e teorias. Nessa postura se busca produzir um conhecimento objetivo, passível ou de ser quantificado, neutro, inquestionável, verdadeiro e supostamente livre de preconceitos ou de qualquer pretensão metafísica ou teleológica (CHALMERS, 1993; SANTOS, 2001).

No contexto escolar, essa concepção de ciência implica na transmissão de uma elevada quantidade de conteúdos ditos científicos, em detrimento das experiências e vivências sócio-culturais dos indivíduos que frequentam a escola. Assim o conhecimento científico veiculado nas disciplinas científicas pode ser concebido como um conhecimento que parece deixar de resolver problemas cotidianos, de ampliar os horizontes cognitivos, bem como deixar de promover a emancipação dos sujeitos que recebem a educação escolar em ciências (SANTOS, 2001). Isso porque os conteúdos de ensino como "amostras de conhecimento" têm usualmente se apresentado uniformizantes, excessivamente livrescos, formais, memorísticos, vazios de interrelações com contextos da realidade, a ponto de configurar um tipo de conhecimento dito "escolar" porque somente parece fidedigno na escola.

Essa concepção de ciência privilegia o caráter instrumental/procedimental ${ }^{4}$ do ensino de ciências em detrimento da compreensão de processos ditos científicos. Também contribui para fortalecer uma crença na possibilidade de "comprovar a teoria no laboratório" ou que a partir do experimento realizado, os alunos consigam chegar "por descoberta" a um determinado conhecimento sem uma mediação teórica que só

\footnotetext{
${ }^{4}$ No sentido de ações mecânicas e pouco reflexivas.
} 
pode ser feita pelo professor, o que acaba reforçando visões distorcidas e equivocadas de produção da ciência e de conhecimento científico (HODSON, 1994; MATTEWS, 1994; BARBERA; VALDES, 1996).

Em vista dos fatores apontados, forma-se um quadro que compromete o desempenho dos professores de ciências, na medida em que durante sua formação não são minimamente instrumentalizados para o trato com questões epistemológicas da Física e do seu ensino.

Na tentativa de minimizar essas dificuldades, professores em exercício, da rede pública, são submetidos de tempos em tempos a cursos de capacitação com conteúdos definidos por instâncias diversas que, em geral, não ouvem o que eles têm a dizer sobre suas dificuldades em sala de aula.

O que se percebe, no entanto, é o pequeno impacto que essas ações têm sobre a prática do professor. O que foi discutido rapidamente é deixado de lado por conta de não ser aceito ou identificado pelo professor como efetivo auxilio no esforço diário para ensinar ciências no ensino fundamental. Não aceito ou identificado pelos professores por inúmeros motivos - falhas na sua formação, cursos/oficinas com programas descontextualizados, materiais inadequados etc. - mas, na perspectiva desse projeto, por eles não terem sido consultados sobre o que gostariam de discutir para melhorar a prática docente.

Em resposta a isso, surgem propostas de parcerias colaborativas entre professores e especialistas ou formadores de professores de Ciências, que se distinguem dos programas pautados na racionalidade técnica pelo caráter de participação e colaboração entre professores e formadores (SILVA; SCHNETZLER, 1999; ROSASILVA; LORENCINI JÚNIOR, 2007).

Nessa perspectiva, é privilegiada a reflexão das práticas pedagógicas dos professores envolvidos, considerando o contexto onde elas acontecem, e tendo a "[...] pesquisa como princípio formador e como prática tornando-se constitutiva da própria atividade do professor, por ser a forma mais coerente de construção/reconstrução do conhecimento e da cultura”. (MALDANER; SCHNETZLER, 1998, p.209).

Sendo assim, não se trata de tentar fornecer para o professor a formação que um licenciando em Física receberia, mas de, em um trabalho coletivo de construção de novos saberes, reconhecer, questionar e buscar superar algumas das limitações no trato com atividades envolvendo experimentos e demonstrações de Física. 


\section{Metodologia}

A coleta de dados para esse trabalho foi feita junto a um grupo de professoras de ciências. Foram realizadas reuniões mensais de novembro de 2007 a dezembro de 2008. Uma escola municipal de Dourados-MS foi escolhida para o local dos encontros. Diversos temas foram tratados ao longo deste período: prática docente, processos de avaliação, relaçao universidade-escola, formação inicial e continuada etc. Para este trabalho foi selecionado o tema experimentação e uso do laboratório de ciências (grifo nosso).

A opção metodológica para o desenvolvimento deste trabalho se fundamenta no pensamento de Vygotski (1995, 2000) que, considerando a crença no papel fundante da dinâmica interativa das relações sociais para o desenvolvimento do indivíduo humano, concebe o homem como um ser que se constitui, se apropria e elabora conhecimentos em processos sempre mediados pelo outro, pelas práticas sociais e pela/na linguagem, nas condições sociais reais de produção das interações. Como a característica desses processos é a transformação, Vygotski (1995, 2000) apresenta alguns princípios metodológicos para sua análise, sugerindo o estudo da história de sua constituição. Segundo ele, "[...] numa pesquisa, abranger o processo de desenvolvimento de uma determinada coisa $[s i c][\ldots]$ significa, fundamentalmente, descobrir sua natureza, sua essência." (VYGOTSKI, 2000, p.74). Nesse aspecto, ele defende um estudo de processos e não de produtos ou objetos, “[...] uma vez que é somente em movimento que um corpo mostra o que é." (VIGOTSKI, 2000, p.86). Defende, também, que numa análise objetiva dos fenômenos, mais do que a enumeração de características externas de um processo, deve-se procurar revelar as relações dinâmico-causais reais. Ou seja, no estudo de um processo, privilegiar uma análise explicativa e não descritiva.

De acordo com Fontana (1996, 2000), ao sugerir esses princípios, Vigotski (2000) explicita os limites da observação na apreensão da dinâmica dos processos e alerta que para apreender o movimento é necessário não só pesquisar dentro dele como também interferir nele. Nesse sentido, considera a intervenção experimental um caminho para tal. Essa intervenção,

[...] entendida como uma atuação sobre as relações em curso no contexto em estudo, jogando com as condições sociais de produção, pode provocar, criar artificialmente um processo de desenvolvimento psicológico, fornecendo-nos indicadores da emergência e da 
apropriação de modos de ação e de elaboração nos sujeitos envolvidos na pesquisa. Esses indicadores aparecem nos percursos, recursos e estratégias compartilhados por nós com eles e entre eles, no decorrer das atividades em que nos encontramos envolvidos. (VYGOTSKY, 2000 apud FONTANA, 2000, p.107).

Pesquisadores que trabalham dentro dos pressupostos de Vigotski (2000), tentando sistematizar alguns de seus princípios metodológicos, os definiram como análise microgenética que implica a busca de

[...] um caminho para documentar empiricamente a presença (ou não) e o grau de transição do funcionamento inter-psicológico para o funcionamento intra-psicológico, durante a solução conjunta de situações problema entre adulto e criança, nos moldes que Vigotski (2000) denominava 'zona de desenvolvimento proximal'". (HICKMANN; WERTSCH, 1978 apud FONTANA, 1996, p.32).

A partir desses princípios teórico-metodológicos, Fontana (1996) ao investigar o processo de elaboração do conceito de cultura no contexto real da sala de aula, concebendo a ação pedagógica como condição da elaboração conceitual pelo aluno, aponta que uma opção para desenvolver um estudo empírico nesse contexto, implicou assumi-lo como espaço para o desenvolvimento de uma análise microgenética do processo de elaboração de conhecimentos. Para essa análise a autora optou pela intervenção experimental, viabilizada pela atuação em conjunto com uma professora das séries iniciais, compartilhando com essa professora o trabalho de pesquisa e coparticipando da configuração da prática pedagógica.

Assumindo esses princípios teórico-metodológicos fundamentados na perspectiva histórico-cultural do desenvolvimento humano e considerando que a prática pedagógica em ciências é determinada pelas condições reais do processo de ensino, é que propomos investigá-la junto a/com professores dessa área. Assim tal como Fontana (1996), nessa investigação procuramos desenvolver uma intervenção experimental, atuando em conjunto com professores de Ciências e compartilhando com eles o trabalho de pesquisa e, também, coparticipando da configuração da prática pedagógica por eles desenvolvidas.

Em face disso, as propostas de elaboração dos procedimentos de intervenção e de observação dessas práticas foram realizadas a partir do planejamento de atividades didático-pedagógicas desenvolvidas em conjunto com as professoras, levando-se em conta os princípios teórico-metodológicos assumidos na pesquisa. O trabalho de coleta 
de dados se deu através de observações naturalísticas e semiestruturadas; realização de entrevistas; análise de documentos escolares; organização discussões coletivas; intervenções refletivas coletivamente; registro em diários de campo e em áudio digital.

A análise de dados se deu conforme orientam: Ginzburg (1989) para a análise das entrevistas reflexivas e discussões realizadas; Bogdan e Biklen (1999) para as observações naturalísticas e semiestruturadas. Por meio da análise dos registros, referentes ao desenvolvimento das propostas elaboradas conjuntamente com os professores, da discussão de suas ações pedagógicas, foram articuladas etapas subseqüentes, em um redimensionamento constante do processo em curso. Nesse processo de construção compartilhada, as propostas elaboradas e desenvolvidas, tendo em vista a prática pedagógica dos professores, constituirão a um só tempo, em procedimentos pedagógicos e procedimentos de investigação, momentos de aprendizagem, de interação, de levantamento de dados, de análise e de reflexão para saber como numa reflexão compartilhada sobre a prática pedagógica em ciências ocorre a reconceptualização do fazer docente.

Em dezembro de 2008, após um ano trabalho, foi realizado o último encontro com esse grupo de professoras. Todas as reuniões foram transcritas e o material resultante foi dividido de acordo com os objetivos do grupo de pesquisa (papel do laboratório nas aulas de ciências, imagens de ciência, relação dialógica professor-aluno e assim por diante). Atualmente, das cinco professoras que participaram dos encontros, duas continuam em contato com os pesquisadores através de um curso de extensão para professores de ciências da rede pública de ensino de Dourados.

\section{Contextualização da escola e dos sujeitos}

A escola tem um papel fundamental na formação dos alunos e o local onde ela está inserida é de grande relevância, tendo em vista que o perfil dos alunos está associado ao local onde moram e que isso influi em seu comportamento.

A escola escolhida para sediar os encontros atende aproximadamente 600 crianças do ensino fundamental do sexto ao nono ano e também a modalidade EJA no período noturno. De acordo com os moradores locais o bairro, formado a partir de um conjunto habitacional, já foi considerado bastante violento, mas isto tem diminuído com o passar do tempo, sendo hoje razoavelmente tranquilo. 
As professoras, então na faixa dos 25 aos 45 anos, tinham tempo de docência variando entre dois e vinte e dois anos. Estavam lotadas em escolas públicas municipais e estaduais. Dividiam sua carga de trabalho entre duas e quatro escolas, atendendo assim um número de alunos que variou de 240 a 540, em pelo menos dois períodos. Todas possuem licenciatura plena em ciências biológicas À época dos encontros, nenhuma das professoras estava inscrita em programas de pós-graduação.

\section{Discussão}

Apresentaremos a seguir dois blocos de fragmentos que acreditamos serem pontos fundamentais para a mudança na percepção das professoras sobre o papel da experimentação. Trata-se dos debates que ocorreram nos dias 19 e 26 de agosto e 14 de outubro de 2008. Os fragmentos dos encontros de 19/08 e 14/10 estão agrupados por conta de temas recorrentes nas falas das professoras. No período em que os episódios foram gravados, já tinha se passado cerca de um ano que o grupo se reunia e, portanto, foram estabelecidos laços de confiança que, inclusive, geraram a motivação para manter a participação das professoras nas reuniões mesmo quando a perspectiva da obtenção de algum certificado - útil para promoção na carreira - não era mais tida como certa.

\section{Encontros: trechos escolhidos}

No encontro do dia 19, fez-se a seguinte pergunta para as professoras: Qual o papel do professor nas aulas práticas ou experimentais [de Física]? E do laboratório [de Física]? Os fragmentos foram agrupados por tema em comum. Abaixo relacionamos trechos das respostas:

\section{$19 / 08 / 2008$}

(R1) Diana: "eu acredito que um dos objetivos além de associar a teoria do professor em sala junto com a prática é criar no aluno, um espírito de investigação. É porque uma das bases da ciência é a investigação, então levar esse aluno a investigar mais até o próprio meio onde ele vive, e também para que ele possa visualizar e comprovar na prática o que foi falado em sala de aula".

(R2) Lucia: "eu vejo como uma interação, maior interação do assunto com os alunos. Poderia fazer uma associação da teoria com a prática, aguçando a curiosidade deles, porque eles vão de repente começar a se perguntar, ai é... e se eu fizesse de tal forma, 
como é que isso ficaria e tal? Eu vejo como esse objetivo, uma interação mesmo".

(R3) Sandra: "o ensino de ciências no meu ponto de vista deve ser colocado no desenvolvimento do espírito critico que a gente tem que levar o estudante, o aluno para pensar. O motivo eu acredito que as aulas experimentais ou práticas são de grande importância, porque elas devem ter como objetivo aproximar o aluno do conteúdo estudado facilitando a compreensão desse conteúdo e outro objetivo que é destacado é a motivação que gera dentro da sala de aula".

(R4) Helena: "a minha pretensão das aulas práticas é levar os alunos a uma aprendizagem comunicativa e contextualizada. De que forma? Depois que eu dei toda a teoria, a fórmula, estou dando a parte física. Então é... questionar com eles. $O$ que vocês aprenderam na Física? Onde eles acham que está inserido a física? $O$ que eles podem trazer pra gente confeccionar dentro da sala? Trocar ideias é... fazer uma parte experimental... para ver um físico em uma palestra [...] tentar através dessas aulas experimentais, montar algum material que possa facilitar o aprendizado [...] a partir daí dessas aulas experimentais que o aluno se sente mais motivado, começa a gostar da matéria [...] eu estou sempre buscando motivá-los de alguma forma".

\section{$14 / 10 / 2008$}

(R5) Helena: Eu acho que o professor tem que fazer papel de mediador durante as experiências, não trazer prontinho: olha aqui está o café, o que está acontecendo com o café ele está evaporando. Eu acho que o aluno tem que colocar a mão na massa e participar de alguma forma, até na universidade eu acho que tem que mudar, sair da rotina um pouco se não o aluno... ai vai ficar nisso. Então vamos fazer umas aulas diferentes no laboratório, no laboratório de tecnologia [sala de informática], de física, de análise, sei lá alguma coisa de gráfico né na prática; então é por aí.

As respostas sugerem uma sobreposição do papel do professor como facilitador ou mediador do trabalho com experimentos e o papel do laboratório nas aulas de ciências (R5). Cabe, então, questionar o grau de percepção das professoras sobre o papel do laboratório nas aulas de ciências do $9^{\circ}$ ano.

A partir dessas respostas iniciais, foi feita uma discussão sobre a necessidade do laboratório nas aulas de ciências. Os pesquisadores alimentam o debate com questões e observações que consideram pertinentes e as professoras colocam suas impressões. Ao final do encontro é distribuído um texto sobre o papel da experimentação nas aulas de ciências (SILVA; ZANON, 2000) e pede-se às professoras que o leiam para fundamentar a discussão nos próximos encontros. 


\section{6/08/2008}

No primeiro bloco selecionamos fragmentos da fala de Diana que indicam o reconhecimento da dificuldade do professor de propor atividades envolvendo o laboratório, mas, em contraste com sua fala no encontro anterior, coloca essa falta de clareza como uma preocupação maior para a universidade e não na sua prática cotidiana. Isso pode ser visto no final de (R11): "Eu não sei por que estou um pouco por fora da questão da universidade. A gente vivência mais o fundamental e o médio”.

Mediador: "Que parte do texto você achou interessante?"

(R6) Diana: Quando ele coloca aqui, a questão da falta de clareza sobre o papel da experimentação na aprendizagem dos alunos.

Mediador: A falta de clareza de quem?

(R7) Diana: Falta de formação do docente, ele coloca que o docente tem essa falta de informação para trabalhar com a experimentação em sala de aula com o aluno. professor?

Mediador: Você concorda que é falta de clareza do

(R8) Diana: Ele deixa claro, em alguns, sim ele coloca em alguns trechos assim essa falta da formação docente e essa falta de clareza de qual é o papel realmente do professor na questão da experimentação.

Mediador: "Qual o papel da experimentação no ensino de ciências?". daqui".

(R9) Diana: "É ele também aborda em alguns parágrafos isso

Mediador: "Como é que, quando ele falou isso, o que você pensou você como professora? Você pensou alguma coisa da sua formação o que você pensa, o que te ocorreu quando falou assim a falta de clareza do professor?". docente?".

(R10) Diana: "A questão da carência na formação

Mediador: "É o que você pensou?”.

(R11) Diana: "Ah, não sei. Da época em que eu me formei até agora? Eu não sei como está sendo agora na universidade. [...] Como é que está o quadro de professores, a carga horária. Eu não sei por que estou um pouco por fora da questão da universidade. A gente vivencia mais o fundamental e o médio". 
Mediador: "De que forma seria sua interação com os alunos, na hora da aula prática...".

(R12) Diana: "alguém leu aqui na página 132, esse autor aqui, Chalmers, ele fala da observação, e aí ele fala da observação... ele fala assim: mesmo considerando que as imagens de dois observadores, o mesmo objeto, no mesmo lugar, sob as mesmas circunstâncias, quer dizer que o aluno, um aluno não vai ter a mesma visão que outro aluno [...] a gente espera isso do aluno e a gente se frustrar, por que a gente se frustra, por que a gente espera uma coisa e muitas vezes a gente não consegue alcançar aquele objetivo [...] Mas esse texto aqui é uma alfinetada".

Já a professora Helena apresenta avanços e recuos na aceitação do papel do laboratório em suas aulas de ciências, chegando inclusive a negar sua efetiva participação como idealizadora e organizadora de um projeto que levou seus alunos da escola estadual em que trabalha para os laboratórios de Química de uma universidade particular de Dourados:

(R13) Helena: "Minha realidade é a seguinte: que três anos eu trabalhei com aulas experimentais, então o que eu vejo, que é uma coisa pronta, é uma fórmula que eles seguem, eles vão lá [no laboratório da universidade particular] seguem aquele roteiro fazem a experimentação e as meninas já tem a resposta, as meninas que estão no projeto inseridas, que são as estagiárias, então quando o aluno, quando você dá o embasamento teórico dentro da sala de aula, o aluno tem o embasamento para questionar certos conceitos durante a experimentação, então o que acontece quando eles querem interagir, eles são cortados, eles não dão oportunidade”.

Mediador: "Dá licença, eu gostaria que a senhora falasse não sobre as estagiárias, eu gostaria [de ouvir sobre atuação da] Helena!".

(R14) Helena: "Não, mas o meu acompanhamento era dentro da sala, o que acontece, eu preparo os alunos pra aula experimental, só que eu espero uma aula experimental dinâmica que eles possam interagir que eles possam observar, eles possam questionar, eles possam fazer outros levantamentos. Só que durante a... aí quando eu levo é uma coisa maravilhosa, eles se comportam, tudo bem, participam, mas é uma coisa assim tão superficial que não é o que eu espero, entendeu? Quando eles questionam dentro da sala de aula, depois da experiência que fizeram, foram lá no laboratório e chegam na sala de aula pra questionar. Então existem várias falhas, tanto minha talvez e também das minhas colegas da... [universidade]"

Mediador: "Quais seriam as suas falhas?". 
(R15) Helena: "A minha falha talvez fosse, não estar intervindo também nessa aula experimental, não tá participando como deveria ser e como ela deveria modificar é, deixando fluir as ideia dos alunos".

[...]

Mediador: "Qual deveria ser a sua participação?”.

(R16) Helena: "A minha participação? Durante a preparação desse material todo, entendeu? Hora que estão preparando material para a experimentação, é isso que vai ser dado. Então é o momento de estar interagindo junto, então, será que isso é propicio para o meu aluno? Será que o meu aluno vai questionar?”.

Mediador: "De que forma seria sua interação com os alunos, na hora da aula prática [...]".

(R17) Helena: "Mas ai eu não posso interferir na aula prática!”.

Mediador: Por que não?

(R18) Helena: Só durante os grupos, mas eu queria falar no geral, que é dar oportunidade para os alunos estarem questionando aquilo lá que eles estão fazendo, entendeu? E não as meninas [técnicas do laboratório] darem todas as repostas prontas, entendeu? Durante o ácido e base... as reações, às vezes não deu certo, então o aluno quer questionar, o aluno quer falar do $\mathrm{PH}$, ele quer falar dos reagentes, da mudança de cor. Então eu falo pras meninas, que são colaboradoras que elas têm que deixar os alunos descobrirem, visualizarem, por que eles têm outro ângulo. Então vamos analisar o que você está vendo e o que o aluno está vendo também, por que elas visualizam de uma forma e o aluno visualiza de outra forma, então por que elas não deixam eles falarem. Ah, mas daí eles vão falar coisas fora do experimento, vai fugir do experimento. Não vai fugir, né?

Helena faz uma crítica ao modo como as aulas são conduzidas no laboratório da universidade e diz claramente o que falta: interação, questionamento, diálogo. Isso pode ser visto em (R13) e (R18). Essa perspectiva vai ao encontro do apontado por Borges (2002, p.303):

O trabalho no laboratório pode ser organizado de diversas maneiras, desde demonstrações até atividades prático-experimentais dirigidas diretamente pelo professor ou indiretamente, através de um roteiro. Todas podem ser úteis, dependendo dos objetivos que o professor pretende com a realização das atividades propostas. Uma alternativa que temos defendido há mais de uma década, e mais recentemente temos investigado e utilizado com nossos alunos, consiste em estruturar as atividades de laboratório como investigações ou problemas práticos mais abertos, que os alunos devem resolver sem a direção imposta por um roteiro fortemente estruturado ou por 
instruções verbais do professor. Um problema, diferentemente de um exercício experimental ou de um de fim de capítulo do livro-texto, é uma situação para a qual não há uma solução imediata obtida pela aplicação de uma fórmula ou algoritmo. Pode não existir uma solução conhecida por estudantes e professores ou até ocorrer que nenhuma solução exata seja possível. Para resolvê-lo, tem-se que fazer idealizações e aproximações.

No entanto, Helena se coloca a parte do trabalho das monitoras do laboratório, pois não pode "interferir na aula prática". Não reconhece/assume que por sua ação, organização e empenho é que seus alunos estão participando de tal atividade e não de outra. Ela teve a ideia, escreveu o projeto, apresentou-o à universidade e conseguiu a sua aprovação. No entanto, tem dificuldade de se enxergar como elemento fundamental para sua efetivação e isso pode ser visto em (R15), (R16) e (R.17).

\section{Considerações finais}

A partir das leituras sugeridas pelos pesquisadores, e dos debates que se seguiram, as professoras começaram a apresentar alguns sinais de questionamento sobre sua prática docente e sobre o uso do laboratório nas aulas de ciências. Os fragmentos escolhidos mostram um dos momentos em que essa reflexão paerece surgir e toma corpo nas suas falas, ora inseguras, ora contraditórias, mas apontando para uma aparente ampliação da percepção da sua participação no processo de construção do conhecimento.

Estabelecer os vínculos necessários entre a formação inicial, a formação em serviço, o acesso à informação sobre pesquisas em ensino de ciências, as demandas burocráticas cotidianas, as relações de grupo professor-aluno e professor-professor e a coerência da prática com o discurso demandam exercício continuo da reflexão e da valorização do fazer docente. Nesse sentido, e reafirmando o que a literatura aponta, é fundamental que os cursos de licenciatura em ciências disponibilizem espaços adequados para a reflexão do futuro professor sobre o papel da ciência, do ensino de ciência e do laboratório na formação dos indivíduos.

Por fim, cabe ressaltar que a experiência vivida junto a este grupo de professoras reforça a necessidade da criação de espaços escolares permanentes de reflexão acerca da formação docente em Ciências, de forma a contribuir para a busca constante de interlocução com temáticas que fomentem a indissociabilidade entre pesquisa, ensino e extensão, conceitos fundamentais na formação dos profissionais dessas áreas. Significa, 
também, envolver professores e pesquisadores do ensino superior, acadêmicos das licenciaturas e pós-graduandos em educação para.

\section{LABORATORY SCIENCE TEACHING AND PRACTICE GROUP OF TEACHING BIOLOGY: REPORT OF A CASE OF COLLECTIVE REFLECTION}

ABSTRACT: The close connection between vision science teacher and his materializing in the form of experimental activities reveals some of the paths constructed in the teaching practice. Considering this and focusing on the 9th year of elementary school, this paper reports and discusses the intervention process and collective reflection on changes in relations between the use of experiments and demonstrations in science, particularly physics, and teaching practices of a group Biology teachers of public schools in Dourados-MS.

KEY WORDS: Teacher training. Science lab. Science teaching.

\section{REFERÊNCIAS}

ARRUDA, S. M.; LABURÚ, C. E. Considerações sobre a função do experimento no ensino de ciências. In: NARDI, R. (Org.). Questões atuais no ensino de ciências. São Paulo: Escrituras, 1998. p.53-60

ASTOLFI, J.; DEVELAY, M. A didática das ciências. Campinas: Papirus, 2006

BARBERA, D.; VALDES, P. El trabajo práctico en la enseñanza de las ciencias: una revision. Enseñanza de Las Ciencias, Barcelona, v.14, n.3, p.365-379, 1996.

BOGDAN, R.; BIKLEN, S. Investigação qualitativa em educação: uma introdução à teoria e aos métodos. Porto: Porto Editora, 1999.

BORGES, A. T. Novos rumos para o laboratório escolar de ciências. Caderno Brasileiro de Ensino de Física, Florianópolis, v.19, n.3, p.291-313, dez. 2002.

CARVAlHO, A. M. P.; PÉREZ, D. G. Formação de professores de ciências: tendências e inovações. 8.ed. São Paulo: Cortez Editora, 2006. (Questões da Nossa Época; 26).

CHALMERS, A. F. O que é ciência afinal? São Paulo: Brasiliense, 1993.

FONTANA, R. A. C. Mediação pedagógica na sala de aula. Campinas: Autores Associados, 1996.

Trabalho e subjetividade. Nos rituais da iniciação, a constituição do ser professora. Cadernos CEDES, Campinas, n.50, p.103-119, 2000. 
GINZBURG, C. Mitos, emblemas e sinais. São Paulo: Companhia das Letras, 1989.

HODSON, D. Hacia un enfoque mas critico del trabajo de laboratorio. Enseñanza de Las Ciencias, Barcelona, v.12, n.2, p.365-379, 1994.

LIBÂNEO, J. C. Adeus professor, adeus professora? Novas exigências educacionais e profissão docente. São Paulo: Cortez, 2006.

MALDANER, O. A.; SCHNETZLER, R. P. A necessária conjugação da pesquisa e do ensino na formação de professores e professoras. In: CHASSOT, A.; OLIVEIRA, R. J. (Org.). Ciência, ética e cultura na educação. São Leopoldo: Ed. UNISINOS, 1998. p.195-214.

MATTEWS, M. R. Historia, filosofia e enseñanza de lãs ciências. Enseñanza de Las Ciencias, Barcelona, v.12, n.2, p.255-277, 1994.

ROSA-SILVA, P. O.; LORENCINI JÚNIOR, Á. Superando conflitos na construção de uma pesquisa colaborativa na escola. Ensaio Pesquisa em Educação em Ciências, Belo Horizonte, v.9, n.2, p.1-18, 2007.

SANTOS, B. S. Um discurso sobre as ciências. Porto: Afrontamentos, 2001.

SILVA, L. H. A.; SCHNETZLER, R. P. A sala de espelhos na formação de continuada de professores de ciências. In: II ENCONTRO NACIONAL DE PESQUISA EM EDUCAÇÃO EM CIÊNCIAS, 1999, Valinhos. Anais do II ENPEC. Valinhos: ENPEC, 1999. 1 CD-ROM.

SILVA, L. H. A.; ZANON, L. B. A experimentação no ensino de ciências. In: SCHNETZLER, R. P.; ARAGÃO, R. M. R. (Org.). Ensino de ciências: fundamentos abordagens. 1.ed. Campinas: R. Vieira Gráfica e Editora Ltda., 2000. p.120-153. 1 v.

VIGOTSKI, L. S. A formação social da mente. São Paulo: Martins Fontes, 2000.

Obras escogidas III. Madrid: Centro de Publicaciones del MEC y Visor Distribuiciones, 1995. 